\title{
Artigo
}

\section{Quatro condições para a pesquisa em psicanálise}

\author{
Daniel Coelho ${ }^{a^{*}}$ iD \\ Eduardo Leal Cunhab \\ aUniversidade Federal de Sergipe. São Cristóvão, SE, Brasil \\ 'Universidade Federal de Sergipe. São Cristóvão, SE, Brasil
}

\begin{abstract}
Resumo: Este artigo discute o uso da psicanálise - em especial da técnica psicanalítica baseada na associação livre - em investigações no campo da psicologia social, a partir da experiência dos autores em um programa de pós-graduação. Para tanto, tentamos produzir uma reflexão sobre as condições e os impactos do deslocamento de conceitos entre a clínica do sofrimento psíquico individual e a pesquisa empírica envolvendo instituições e grupos. Centrando-se na afirmação do primado do inconsciente, os autores procuram ordenar as linhas de aproximação e de afastamento entre a clínica e a pesquisa empírica. Parte-se da discussão sobre as condições necessárias (fora do setting terapêutico) à escuta do inconsciente, ao estabelecimento do vínculo transferencial, ao trabalho de interpretação dos discursos dos sujeitos, e, por fim, à elaboração de conteúdos e desejos inconscientes - seja por parte dos sujeitos escutados da pesquisa, seja por parte do próprio pesquisador em seu trabalho de elaboração teórica.
\end{abstract}

Palavras-chave: psicologia; psicanálise; metodologia de pesquisa.

\section{Introdução}

O tema da pesquisa em psicanálise frequentemente aparece restrito à sua dimensão clínica (Lo Bianco, 2003), centrado numa interrogação sobre a eficácia da psicanálise como método terapêutico e na busca da comprovação dessa eficácia e sua vinculação com aspectos particulares da técnica. Parece, aliás, ser esse o sentido mais usual da expressão pesquisa em psicanálise (Malan, 1981).

A clínica é certamente o campo empírico inaugural da psicanálise, em que são forjadas suas regras técnicas e sua reflexão ética; mas não é o campo exclusivo do inconsciente. Assim, a reflexão sobre os procedimentos na clínica pode produzir uma direção para os procedimentos de pesquisas que não são clínicas. Retomamos, dessa forma, questões sobre as possibilidades e os limites do que se denomina, muitas vezes, "psicanálise aplicada" - que se distinguiria de uma psicanálise pura, idealmente submetida ao setting e à prática da clínica privada (Birman, 1994); ou, na terminologia lacaniana, questões de uma psicanálise em intensão ou extensão (Aragão, Calligaris, Costa, \& Souza, 1991); ou, ainda, de uma psicanálise extramuros como a clínica implicada politicamente (Rosa, 2016).

A discussão sobre a técnica psicanalítica, que sustentaria a enunciação de um possível método de pesquisa, diz respeito, sobretudo, às condições de reconhecimento do inconsciente. Ela aponta para a suspensão das funções do eu - tanto no discurso que se pede do paciente como na escuta que se exige do analista (Cunha \& Coelho, 2015) -, e para a interdição

* Endereço para correspondência: daniel7377@gmail.com das satisfações do eu, na abstinência exigida em relação à transferência e no controle sobre o qual se deve manter a contratransferência, numa discussão que parte da crítica de Freud às práticas de hipnose e sugestão de seus mestres. O debate não envolve apenas a reflexão sobre a eficácia clínica dos métodos, mas também o desenho de uma postura ética e política (Coelho \& Birman, 2014). Freud narra, por exemplo, seu desconforto com a prática de Bernheim de interditar, com veemência, a resistência de seus pacientes à sugestão; para o autor isso era uma "evidente injustiça e uma violência", uma vez que o paciente "tinha direito a contrassugestões [isto é, a resistir] certamente, se tentavam sujeitá-lo com sugestões" (Freud, 1921/2011, p. 41).

Em seu percurso, a sugestão - a influência do médico sobre o paciente - é reduzida a um mínimo: ao invés de exortar a rememorar, convida a associar (Freud, 1925/2011, pp. 120-121). Assume-se um lugar de escuta, indiferente quanto ao destino da fala, e qualquer intervenção é justificada e medida apenas pela produção de novas associações - logo, pela continuação do discurso do paciente (Freud, 1911/2010, 1937/1969). Fazer prosseguir o trabalho de associação é a tarefa principal do analista; qualquer outra deve estar subordinada a essa, inclusive aquelas ligadas aos interesses científico e terapêutico (Freud, 1912b/2010, 1915a/2010). Subordinar esses interesses à prática da associação livre produz, na verdade, suas redefinições, colocando-os a serviço da descoberta do inconsciente. Desse modo, a pesquisa psicanalítica deve fundamentar-se na possibilidade da enunciação do inconsciente, e sua reflexão metodológica pode ser descrita como a discussão sobre as condições dessa enunciação. 
Tomando como ponto de partida os achados, questionamentos e preocupações acumulados no decorrer de alguns anos de trabalho em um programa de pósgraduação em psicologia social, no qual orientamos alunos em pesquisas de campo com grupos e instituições sociais e tendo como referencial teórico e metodológico a psicanálise, organizamos uma discussão dessas condições em quatro blocos:

Partiremos das condições de escuta, apropriando-nos das regras de ouro - associação livre e escuta flutuante como princípios de pesquisa, organizadores dos seus procedimentos, e, portanto, de sua empiria e de sua ética. Isso molda o tipo de interlocução estabelecido com os sujeitos da pesquisa e direciona algumas preocupações com a coleta de dados, como o registro do material. Nas condições de transferência, discutiremos as implicações do pesquisador no objeto de sua pesquisa, apontando para a ética da abstinência frente ao fenômeno transferencial. Nas condições de interpretação, definiremos a interpretação na clínica como uma operação de restituição da palavra. Levantaremos os problemas da implicação do pesquisador em suas interpretações e de seu papel preliminar às elaborações. Finalmente, nas condições de elaboração, discutiremos a noção de trabalho (Arbeit) em Freud, em seus aspectos de disfarce do material inconsciente e de transformação psíquica, problematizando a possibilidade de elaboração por parte dos participantes da pesquisa. Também situaremos a elaboração teórica em articulação à elaboração psíquica, discutindo, com isso, a produção do texto que finaliza a pesquisa.

Essas condições interferem umas nas outras e não apresentam limites muito claros, mas, ainda assim, servem como pontos de ancoragem para operacionalizarmos, nos termos da prática da pesquisa de campo, a postura ética que possibilita o reconhecimento do inconsciente.

\section{Condições de escuta}

Já defendemos, em outros lugares (Batista \& Cunha, 2012; Cunha \& Coelho, 2015), que as regras de ouro da associação livre e da escuta flutuante devem ser o ponto de partida para a discussão dos procedimentos de qualquer pesquisa apoiada no método psicanalítico. Isso implica a suspensão das funções do eu, refletida nas dicas práticas que Freud dá ao analista iniciante em 1912: não é preciso memorizar nem anotar o que o paciente diz; devemos abrir mão de qualquer tentativa de ordenamento sobre o material; ao contrário, devemos deixar que o material conduza a atenção, que, de outro modo, permanece difusa, e deve poder acompanhar também as cadeias inconscientes do analista. As funções de ordenamento do eu são deixadas de lado, suspensas, para que se produza uma comunicação entre inconscientes, segundo a imagem proposta por Freud (Freud, 1912b/2010).

Apontamos, também (Cunha \& Coelho, 2015), que a transposição das regras que organizam a clínica para a prática da pesquisa de campo esbarra em uma série de dificuldades. A situação de pesquisa é diferente da situação clínica que Freud aponta como ideal. $O$ pesquisador não vai a campo sem antes ter passado por uma revisão bibliográfica e pela elaboração de um projeto - ao contrário do clínico, que recusa qualquer meio sistemático de obter informações sobre seu paciente, assim como qualquer tentativa de articulação teórica do caso antes que esteja terminado. O pesquisador, ao contrário, tem, de antemão, interesse em seu objeto de estudo e também uma grade teórica a partir da qual pode delimitar um problema específico de pesquisa que lhe sugere uma hipótese de trabalho. A pesquisa frequentemente busca apenas a corroboração dessa elaboração teórica prévia. Estamos, portanto, distantes das condições que Freud acreditava ideais para o trabalho analítico, longe de podermos exercer com rigor a escuta flutuante.

No entanto, é preciso considerar que as regras freudianas não são protocolos rígidos; elas indicam parâmetros mínimos de ação e indicam uma postura ética que norteia o psicanalista. A escuta flutuante afasta a possibilidade de encaixar apressadamente um paciente no que a teoria prevê, mas ela própria é dependente de uma teoria, que presume que uma escuta desse tipo poderia levar a uma interpretação que decifre o sintoma como uma formação do inconsciente. A associação livre do paciente, a seu passo, jamais é realmente livre - mas, como tarefa colocada no horizonte, leva ao reconhecimento e à superação das resistências. Ademais, é falso que o analista receba seus pacientes no consultório de modo neutro, desimplicado e ateórico, o que Freud acreditava ser o ideal. O analista do setting clássico tem, obviamente, uma grade teórica que o orienta - é um psicanalista, e talvez um lacaniano ou um winnicottiano - assim como óbvios interesses e desejos implicados em seu trabalho. O que afastaria o trabalho de pesquisa da situação clínica ideal, dessa forma, não seria a diferença propriamente dita entre a clínica e a pesquisa, mas sim a diferença entre uma proposta ideal e sua colocação em prática.

Dessa forma, é no horizonte, como ideais que nos fornecem parâmetros mínimos de ação, regulados por uma postura ética, que a associação livre e a escuta flutuante guiam nossa prática de coleta de dados. Deixamos os roteiros de entrevistas de lado, preferindo a colocação de perguntas mais vagas e mais abertas, que sirvam como disparadores do discurso dos sujeitos; as perguntas subsequentes virão, também, a reboque desse discurso. Nisso, aproximamo-nos do modelo que podemos destacar da pesquisa de Ana Cristina Figueiredo (1997) sobre o trabalho do psicanalista no ambulatório público. Ela conta que, no decorrer de sua pesquisa, foi levada a deixar de lado roteiros de entrevista em prol de uma conversa com tom mais espontâneo, encadeada e continuada pelos assuntos que surgissem, sendo a direção da entrevista deixada a cargo do entrevistado, e não do entrevistador.

Quanto ao registro do material, ele deve atender a alguns requisitos que Freud indica em sua 
pequena discussão sobre o mesmo problema na clínica (Freud, 1912b/2010; Cunh \& Coelho, 2015). Sua recusa à prática de fazer anotações é embasada em alguns aspectos: a anotação toma a atenção do analista, e é preciso que ela esteja disponível e dispersa, "uniformemente suspensa"; as notas comportam sempre uma dose de elaboração secundária, pois selecionam, ordenam e fixam o que se escutou. A prática de notas é recusada, portanto, na medida em que reintroduz as funções secundárias do eu que a regra da atenção flutuante tenta suspender.

A gravação, por outro lado, é um meio de registro que dispensa a atenção do entrevistador e registra sem elaborar. Assim, a gravação integral e sem cortes, que registre tudo o que for dito, é nossa estratégia de preferência. Ao mesmo tempo, alertamos que a fidedignidade de registro da gravação não afasta a consideração de que ela também funcione, no decorrer da pesquisa, segundo o descrito pela teoria freudiana da lembrança. Do gravado até o transcrito e publicado, temos, evidentemente, muita seleção e elaboração de material, e essa última é sempre oportuna ao esquecimento e à lembrança encobridora (Freud, 1899/1969).

O que dissemos sobre a entrevista e a gravação procura definir padrões mínimos de ação, e não devem ser tomados com rigidez. As condições nas quais acontece a pesquisa - seu setting - são determinantes. No caso de uma pesquisa sobre um grupo de adesão ao tratamento para portadores de HIV, as entrevistas foram substituídas por conversas informais em salas de espera, nos setores administrativos, ou antes e depois das reuniões habituais do grupo (Santos, 2012). No caso de uma pesquisa com pacientes candidatos à cirurgia bariátrica, a coleta de dados, inicialmente pensada sob a forma da entrevista semiestrurada, também tomou a forma de conversa informal na sala de espera, situação em que a pesquisadora encontrou uma chance melhor de não ser confundida com um membro da equipe responsável por mais uma avaliação (Sobral, 2013). O cotidiano do trabalho de uma psicóloga em um Centro de Referência de Assistência Social (CRAS) tornou-se campo de uma pesquisa sobre as políticas públicas de assistência social (Souza, 2012). Em todos esses casos, foi imposto um modelo mais próximo da etnografia, e a confecção de notas feitas a posteriori, de memória. A elaboração secundária implicada foi retomada na reflexão metodológica como efeito contratransferencial (Souza \& Coelho, 2014).

Ainda sobre o setting, em uma pesquisa sobre adolescentes que, ao atingirem a maioridade, são desligadas dos abrigos institucionais nos quais estavam alojadas, a pesquisadora foi recebida na instituição e encaminhada a uma sala na qual deveria aguardar o fim de uma reunião da equipe técnica - era a sala em que eram arquivados os prontuários das adolescentes. Ali estavam suas fichas, os registros de seus atos, ocorrências, procedimentos. Muito do que, certamente, as adolescentes teriam motivos para não quererem que outros tivessem acesso. Assim, a pesquisadora encontrou, no silêncio eventual das entrevistadas, um limite incansavelmente desrespeitado, presentificado na própria sala em que foram alocadas (Santana, 2015).

Outra pesquisadora relatou sentir-se encarcerada quando ia ao abrigo para mulheres vítimas de violência doméstica em que realizava sua pesquisa. Portões, portas e janelas são mantidos fechados por exigência do regimento interno. Nas entrevistas, as mulheres diziam estar presas, enquanto seus agressores estavam na rua. Diziam, ainda, que a culpa era delas mesmas. A pesquisadora, em sua posição, sentiu pena e, ao ouvir as gravações, surpreendeu-se com um ato falho que havia lhe passado despercebido no momento da entrevista: a entrevistada reclama de "estar ali obrigada" (ao invés de "abrigada") (Fonseca, 2015, p. 60).

\section{Condições de transferência}

Como Freud alerta em diversas ocasiões, a associação livre é uma tarefa fadada ao fracasso diante das resistências que enfrenta. Esse fracasso, porém, revela as resistências, primeiramente naquilo que o paciente não diz - quando muda de assunto ou se cala - e, logo depois, no terreno da transferência - na atualização de conflitos e desejos inconscientes na relação entre analista e analisando, no qual aquilo a que se resiste no discurso se revela em ato (Freud, 1914/2010).

A transferência revela-se o campo próprio da experiência psicanalítica. Ali, o inconsciente não é mais uma lembrança afastada e esquecida, alcançável apenas pela rememoração, mas algo presente e consistente, repetido na relação com o analista como coisa atual. O sucesso da análise depende dessa atualização, já que não é possível, segundo a imagem freudiana, liquidar alguém in absentia ou in effigie (Freud, 1912a/2010). É essa experiência que forma, como um espaço entre a realidade e a fantasia sustentada numa relação com um outro, o terreno no qual a psicanálise pode reivindicar sua própria noção de empiria (Birman, 1994), e assim contrapor-se às psicologias objetivantes (Lacan, 1966/1998, p. 215).

O fenômeno da transferência não está separado do que se designa como contratransferência, ou seja: a presentificação do inconsciente não se resume à projeção que o paciente faz sobre $o$ analista de seus anseios e fantasias. Há que se contar, também, que o analista participa disso isto é, a projeção dessas fantasias produz efeitos sobre ele e despertam seus afetos. Assim, a cena da transferência se constitui não apenas a partir do impacto subjetivo que a presença do analista tem no paciente, mas também do impacto subjetivo que a presença do paciente tem no analista. O fenômeno contratransferencial - afetos e implicações que o paciente desperta - é fortemente articulado com a imagem da comunicação entre inconscientes, e faz depender dela a própria prática da interpretação (Freud, 1912b/2010, p. 156).

No ambiente extramuros, o trabalho analítico possui um forte caráter contratransferencial. $\mathrm{O}$ interesse 
por determinado tema sempre traz as marcas da história, do desejo e da subjetividade do pesquisador e, como já colocamos acima, a ida ao campo é antecedida por uma pesquisa bibliográfica, pela construção de um problema de pesquisa e eventualmente pela apresentação de uma hipótese.

A regra da atenção flutuante procura suspender tudo isso no momento da escuta, mas seu sentido não é o de impedir que o pesquisador seja afetado por seu campo; ao contrário, ele busca para isso melhores condições que tornem possível uma leitura transferencial importante no momento da interpretação. $\mathrm{O}$ reconhecimento da inevitabilidade do fenômeno transferencial, a retomada crítica do seu material na elaboração do trabalho, assim como o apontamento dos fatores contratransferenciais em orientações e conversas entre pares são importantes para reconhecer e "controlar" a contratransferência - seja impedindo que as expectativas teóricas do pesquisador determinem a fala dos sujeitos escutados (e o rumo da pesquisa como um todo), seja avisando que sua eventual vontade de ajudar aqueles que escuta produz uma gratificação que tampona uma angústia que serve de motor à fala do sujeito e à pesquisa como um todo.

Freud (1915a/2010) enuncia sua regra de abstinência partindo de uma crítica à moral como balizadora da relação estabelecida entre analista e paciente. Em seu raciocínio, isso implica a admissão plena do apaixonamento pelo qual pode passar sua paciente, ao mesmo tempo que indica, como condição para tal, que o processo terapêutico deva ser conduzido sem retribuição, mas também sem rechaço - isto é, em abstinência - daquilo que constitui a transferência, reproduzindo o que norteava a própria postulação da escuta flutuante. Mesmo que em ato, a transferência deve ser considerada como algo que o paciente diz, e, portanto, não pode ser rechaçada como inconveniente ou interditada.

As possibilidades de retribuição, por sua vez, estão vetadas não apenas porque impedem as forças que impulsionam a análise, mas sobretudo pelas obrigações éticas do analista para com o seu trabalho. É ele que, ao instaurar o dispositivo analítico, evoca a paixão transferencial - isso o torna responsável pelo fenômeno, e impede que se sirva dele para obter vantagens pessoais. A evocação se justifica na medida de uma promessa clínica, que envolve restaurar, no paciente, suas capacidades de amar e de se relacionar com o outro, de modo que isso signifique um "aumento da liberdade psíquica” (Freud, 1915a/2010, p. 226). Essa liberdade é apresentada como um valor em si, e é a mesma que está em jogo em sua crítica à hipnose.

Retornando ao campo da pesquisa, a transferência exige, ainda, a reflexão a respeito dos efeitos da presença do pesquisador sobre seu campo de atuação, o modo como os sujeitos o tomam e as demandas que lhe fazem. Vale lembrar o exemplo da pesquisa sobre pacientes bariátricos (Sobral, 2013), citada anteriormente, em que era importante que a pesquisadora não fosse tomada como parte da equipe médica, uma vez que a fala dos sujeitos já estava contaminada demais pelos discursos técnicos da medicina. É também interessante notar que a equipe que recebeu a pesquisadora no abrigo para mulheres vítimas de violência tenha lançado-lhe um desafio, dizendo que a tarefa de ouvi-las não seria fácil, prontificando-se também a contar suas experiências, pedindo dicas de como lidar com as abrigadas e, especialmente, pedindo que a pesquisadora ajudasse a compreender um enigma: por que tais mulheres insistem em permanecer com os homens que as violentam (Fonseca, 2015). Da mesma forma, quando membros de uma torcida organizada ameaçada de banimento dos estádios por episódios de violência dizem que a convivência demonstrará à pesquisadora que eles não são tão violentos quanto dizem, a fala é interpretada como uma demanda pelo reconhecimento como grupo autônomo capaz de autorregulação, funcionando frequentemente como um pedido de que ela sirva de porta-voz e defensora do grupo perante representantes do Estado. A pesquisadora não podia, evidentemente, tomar esse papel, mas tampouco podia afastar em definitivo a esperança do grupo em encontrar, nela, uma salvação para a agremiação, dado que era isso que sustentava a participação deles na pesquisa (Batista \& Cunha, 2012).

\section{Condições de interpretação}

A interpretação dos sonhos (Freud, 1900/1969) apresenta a seguinte tese, definidora da prática psicanalítica: um sonho, assim como um sintoma neurótico, é interpretável. Sua aparência absurda pode ser explicada como um precipitado de pelo menos dois desejos, um dos quais deve passar por uma série de deformações por conta da ação da censura. A tese propõe, ao mesmo tempo, um método para a interpretação que basicamente consiste em pedir ao sonhador que associe livremente (Freud, 1900/1969, p. 108; 1916-1917/2014, p. 135).

É com o material dessas associações que se produz a interpretação do sonho. A operação consiste em restituir, àquele que sonhou, a palavra perdida na deformação do material inconsciente implicada na formação de compromisso que é o sonho (e também o sintoma); ou seja, busca-se, por meio da interpretação, apontar o elemento recalcado.

A palavra do paciente é ainda o próprio índice pelo qual podemos avaliar a verdade de uma interpretação; não no sentido da concordância ou da discordância do paciente, mas sim no da produção de material novo, de uma nova lembrança, uma nova associação que testemunhe a derrubada de uma resistência (Freud, 1937/1969).

Dessa forma, a interpretação consiste em uma restituição da palavra: ao pedir que associe, ao apontar para o recalcado, e ao esperar do discurso do paciente uma associação (e não uma concordância).

Assim, fazer com que o paciente bariátrico fale (ao menos um pouco) já é interpretar. Restitui-se, desse 
modo, seu lugar de sujeito, ainda que seja na sala de espera das consultas nas quais o analisado será avaliado e talvez culpabilizado por não conseguir o Índice de Massa Corporal (IMC) necessário para a tão sonhada cirurgia, por meio da qual espera alcançar padrões físicos ideais, com os quais finalmente conseguiria alcançar o amor do outro - coisa idealizada por excelência (Sobral, 2013).

É como restituição de palavra que também podemos entender a interpretação segundo a qual uma torcida de futebol encontra, na confrontação violenta com torcidas rivais, o meio de garantir que suas tensões internas não ameacem sua coesão. A violência da briga com a torcida rival e sua colocação como inimigo possibilita os fortes laços que unem aqueles sujeitos uns aos outros e à paixão pelo seu time de futebol. Seria, então, necessário restituir à violência desse grupo outro lugar que não o de algo indesejado que deve ser contido (como quer o discurso do Estado e da "sociedade"), nem o de uma impressão errada que deve ser desfeita, como afirmam manifestamente os torcedores. Ela é constituinte dos laços que os unem, e organiza o campo dos afetos: violência e ódio para fora, amizade e coesão para dentro. Nesse sentido, a violência do encontro com a torcida inimiga é o signo ambíguo dos laços de amizade que os unem (Batista, 2011).

Retornando a Freud, no entanto, podemos levantar dois problemas na tese de que a interpretação é a restituição da palavra: o primeiro é a participação do próprio analista na construção do material interpretativo. Se é verdade que deve haver uma comunicação entre inconscientes, e se é verdade que a interpretação está intimamente relacionada com o despertar dos afetos do analista na situação de transferência, o analista está aí implicado, e a interpretação não é feita puramente do discurso do paciente. Dito de outro modo, a interpretação jamais deixa de ser uma arbitrariedade, e o que se restitui não é a palavra original, mas sim uma interpretação - no sentido da precariedade e da parcialidade de uma opinião, de um ponto de vista do analista (Batista \& Cunha, 2012).

$\mathrm{O}$ segundo problema refere-se à resposta esperada da interpretação. Como já colocamos, não se trata de aceitá-la ou não; o que se espera é que produza efeitos, deixando surgir material antes inacessível. Isso trata-se, porém, apenas de um trabalho preliminar: o que a interpretação aponta só produzirá seus efeitos depois de um longo tempo de elaboração, por meio de um trabalho psíquico solitário do paciente, no qual ele deve encarar suas próprias resistências, e pelo qual o analista deve aguardar pacientemente (Freud, 1914/2010, 1937/1969).

A paciência com que aguardamos o trabalho de elaboração do paciente é correlativa à ética que protesta contra a violência da sugestão, que defende que o paciente deva ter seus direitos de resistência um pouco mais respeitados ao mesmo tempo que propõe as consequências dessa ética na própria noção de cura, uma vez que é o trabalho solitário de elaboração do paciente, a respeito do qual o analista nada pode fazer além de esperar, que constitui a novidade da psicanálise em relação aos tratamentos por sugestão (Freud, 1914/2010).

\section{Condições de elaboração}

Elaboração (em alemão "Arbeit", que pode ser traduzido simplesmente por "trabalho") é uma noção geral que descreve a atividade de transformação do material psíquico, aparecendo ao longo da obra freudiana em diferentes contextos e em diversas formas compostas.

Consideremos primeiramente a elaboração onírica ou trabalho do sonho (Traumarbeit), ou seja, a série de transformações e disfarces a que deve se submeter o pensamento onírico na formação de um sonho - desde os mecanismos inconscientes de deslocamento e condensação, passando pela figurabilidade, até o papel da elaboração secundária (sekundäre Bearbeitung). A descrição dos elementos de processamento do sonho leva Freud a considerar que, nele, chega-se ao ponto da "transvaloração de todos os valores psíquicos" (Freud, 1900/1969, p. 542). Na elaboração onírica, tais processos são colocados em andamento pela necessidade de distorcer e disfarçar o material, tornando-o aceitável para a continuação do sono do eu, e devemos reconhecer que há aí um sentido original que pode se perder.

Tais considerações estão presentes na nossa reflexão sobre o registro do material de pesquisa: a recomendação do registro integral das entrevistas garante alguma fidedignidade ao material, mas trata-se apenas de um ponto de partida para uma série de operações que levarão à confecção do trabalho final. O material original será submetido a uma série de transformações. $\mathrm{Na}$ transcrição, o registro da fala deve se transformar em texto, que será articulado a outros, tanto advindos de outras entrevistas quanto da própria teoria. Do gravado ao transcrito e publicado, o material será trabalhado, elaborado, e, como já dito, a elaboração é sempre uma oportunidade para a lembrança encobridora.

A série de distorções aplicadas ao material do sonho não esgota o sentido do termo Arbeit na obra freudiana. Destaquemos, também, que o termo aponta para a transformação como necessidade de reorganização do psiquismo. Mediante uma perda, o sujeito deve proceder a uma série de operações de desligamento da libido investida no objeto que não se encontra mais na realidade; ou seja, deve proceder a um trabalho de luto (Freud, 1917/2010), após o qual poderá dispor daquela libido para o investimento em um novo objeto. A experiência de rememoração e de repetição na análise leva o sujeito a enfronhar-se em suas próprias resistências, elaborando-as e superando-as. É esse trabalho que produz os maiores efeitos modificadores sobre o paciente (Freud, 1914/2010). Assim, a elaboração não corresponde apenas às distorções produzidas pelas exigências da censura na formação do sonho, mas também descreve reordenamentos psíquicos profundos, como os supostos no luto e na análise. 
Cabe, então, perguntar se nossas pesquisas poderiam ter, elas também, algum efeito de elaboração de um reordenamento psíquico profundo para aqueles que foram escutados. Para isso, devemos ter em mente que os períodos de idas a campo são curtos, e que as interpretações (tanto no sentido clínico do desvelamento do inconsciente quanto no sentido acadêmico do ordenamento sintético do material e da formulação de hipóteses a partir dele) são, por isso mesmo, guardadas para um momento posterior. Ainda que haja uma devolutiva no fim do processo, no qual os interessados são informados sobre os destinos do trabalhoe que isso possa produzir algum efeito de elaboração -, não podemos nos arrogar o caráter clínico presente em outros estilos de pesquisa, tal como a psicanálise implicada de Miriam Debieux Rosa (2016), que coloca a tarefa de elaboração em primeiro plano e entende a transferência como estratégia para que aquele que fala aproprie-se do seu próprio discurso (Rosa \& Domingues, 2010).

Ao mesmo tempo, devemos considerar também que toda entrevista tem uma dimensão performativa de ato, que se constitui frequentemente em ponto de partida para um trabalho de elaboração do sujeito da pesquisa. Trata-se de um efeito inevitável dado pela própria situação de pesquisa. Não obstante, o que desejamos ao fazer retornar o resultado do trabalho aos sujeitos que participaram dele é produzir um efeito de interpretação que possa convocar os sujeitos à elaboração.

\section{Elaboração teórica}

Por outro lado, a produção teórica da psicanálise deve ser também compreendida como trabalho de elaboração. É o destino final da experiência transferencial do analista, de onde são recolhidos os fenômenos que devem ser descritos, organizados e articulados a ideias abstratas na teoria. Quanto aos conceitos aí gerados, eles não possuem mais do que um caráter de convenção, e não toleram definições demasiado rígidas (Freud, 1915b/2010, p. 52-53). São “mitos", especulações que valem por seu caráter heurístico, ou seja, pelo que permitem "descobrir" - o que deve ser articulado também com a prática da interpretação, que toma seu sentido pela descoberta de novos elementos e pela produção de novas associações. Desse modo, a própria ideia de elaboração sustenta uma aproximação entre o trabalho teórico do analista, ou do cientista, e o fantasiar da criança.

Freud adverte quanto à diferença entre as "atitudes psíquicas" necessárias à análise e à especulação teórica. A atitude psíquica da análise está indicada na escuta flutuante e na postura abstinente; enquanto a atitude psíquica do cientista implica numa sistematização que compõe uma estrutura e prevê o prosseguimento do caso, e, para isso, não pode dispensar a especulação e a cogitação. Daí, a recomendação de que a elaboração teórica, o "trabalho sintético do pensamento" (synthetischen Denkarbeit) fique para depois de encerrado o tratamento do paciente (Freud, 1912b/2010, pp. 153-154).
Há outro fator que deve ser destacado quanto à recomendação de deixar a elaboração teórica para depois: o impacto da transferência, situação na qual, lembremos, o analista também está implicado. É preciso que esse impacto tenha se tornado lembrança para que se possa elaborá-lo. É apenas após o término da análise de Dora que Freud consegue vislumbrar a sua própria parte no fracasso daquele tratamento: que sua interpretação estava montada num preconceito, que se exprimia em sua contratransferência (Lacan, 1966/1999).

O retorno aos diários de campo e gravações de entrevistas coloca o pesquisador numa posição terceira quanto a si próprio e à experiência que esse material retrata (Figueiredo, 1997). Como já apontamos, trata-se de uma razão para relativizar a fidedignidade de tais arquivos, ao mesmo tempo que é a condição de possibilidade para notar detalhes que haviam escapado à primeira escuta. É aqui, ainda, que o pesquisador pode estranhar a si próprio, e reconsiderar o que ali se passava transferencialmente.

Assim, a pena da pesquisadora em relação às mulheres vítimas de violência (Fonseca, 2015) não aponta apenas a identificação que a faz sentir uma parte do sofrimento pelo qual essas mulheres passam; é o que se repete sem parar: as vítimas da violência são, de um modo ou de outro, sempre colocadas como aquelas que devem pagar uma pena por algo que cometeram. Isso está nos discursos dos maridos violentos como justificativa dos seus atos. Também está no discurso das mulheres, que dão como razão para estarem no abrigo o fato de terem deixado que a violência de seus maridos chegasse ao ponto da mutilação de seus corpos e da ameaça às suas vidas. Está, ainda, na estruturação das normas do abrigo, que resolvem as questões de segurança e sigilo necessárias para seu funcionamento pelo estabelecimento de normas estritas que lembram a disciplina prisional, e também no discurso dos servidores do abrigo, que desafiam a pesquisadora a explicar por que essas mulheres voltam para seus maridos violentos.

Ao mesmo tempo, a elaboração do trabalho acadêmico é correlativa à produção de uma rede de inteligibilidade, que articula a escuta e a interpretação da experiência de campo ao saber acadêmico e à cultura em geral, de modo que resulte disso algo que seja partilhável, na forma de um texto que se ofereça a uma leitura.

Podemos apontar uma direção para essa elaboração. Como insistimos, partimos da escuta, e isso significa colocar as falas dos sujeitos em primeiro plano porque é delas que surge uma interpretação, e é com elas no horizonte que a elaboração deve seguir. Nesse sentido, a repetição de um significante - "família" - foi o ponto a partir do qual uma pesquisa sobre instituições de abrigamento para crianças e adolescentes pode ser elaborada (Souza, 2012). Os abrigados falavam em duas famílias: a de dentro e a de fora dos abrigos. Os funcionários, por sua vez, falavam como pais dos abrigados, e, ao mesmo tempo, como filhos abandonados do Estado. Essa repetição ensejou uma análise da história 
dos abrigos, que sugeriu que eles são instituições que atuam como lares substitutos e cujo surgimento está intimamente ligado à idealização do núcleo familiar pela medicina higienista. O modelo é tão presente na organização do Estado e em suas leis que impede, no caso dessas crianças e adolescentes, a constituição de qualquer outro laço, sempre medido pela sua precariedade diante do modelo idealizado.

Desse modo, a especulação teórica deve estar sempre ancorada no que os sujeitos disseram, e deve demonstrar o elo que existe entre esse material e aquele que é despertado na transferência. Ao mesmo tempo, se reconhecemos na transferência a parte do analista ou do pesquisador, é claro que indicamos nisso, também, um limite do trabalho, na medida em que, por mais que nos esforcemos em colocar em primeiro plano o dito pelos sujeitos da pesquisa, é sempre a experiência singular do pesquisador o que ali se elabora. Assim, indicam-se, nessa última etapa, o alcance e os limites do trabalho analítico de investigação de fenômenos socioculturais, bem como uma discussão sobre o próprio estatuto do conhecimento produzido no contexto dessas pesquisas e, no fim das contas, de toda e qualquer formulação teórica produzida a partir da experiência psicanalítica.

\section{Conclusão}

Para concluir, acreditamos ser importante retomar aqui o que consideramos ser os elementos centrais desse deslocamento do trabalho do analista do ambiente estrito do setting clínico para o campo ampliado das instituições e do corpo social.
Nosso ponto de partida é uma ética que consiste, por um lado, no acolhimento irrestrito da escuta, e, por outro, na postura de abstinência quanto à transferência. Insistir que se trata de uma ética implica necessariamente admitir a parcialidade do saber que produzimos, na medida em que estão amarrados a certos valores - como o da "liberdade psíquica" defendida por Freud. Lembremos ainda que a discussão sobre essa liberdade não se restringe à "análise do eu", mas perpassa também a "psicologia das massas", o que evidencia a articulação reivindicada por Freud entre psicologia individual e social.

É a partir dessa ética, traduzida na discussão dos procedimentos, que abordamos nossos objetos de estudo e que esperamos explorar tal articulação entre indivíduo e sociedade por meio da valorização da noção de Inconsciente.

É, também, a partir de tal ética que buscamos estabelecer as fronteiras mínimas de uma empiria que, precisamente, coloque em primeiro plano o inconsciente e todo o campo fenomênico que lhe está associado, como, por exemplo, a dimensão pulsional da experiência subjetiva. Em termos mínimos, ela se sustenta na delimitação dos moldes de uma escuta e reconhece os efeitos da transferência, assim como a necessária parcialidade das interpretações e das elaborações teóricas. Indica-se, portanto, não apenas as condições de produção do saber a partir da psicanálise, mas também o sentido último de tal produção - a elaboração de uma experiência transferencial de confronto com o inconsciente - e seus limites - os de um saber produzido em uma situação singular, por sujeitos determinado, sujeito ao caráter contingente de uma experiência.

\section{Four conditions to research in psychoanalysis}

Abstract: Our article discusses the use of psychoanalysis and especially the psychoanalytic technique based on free association in investigations on social psychology, based on the authors' experience in a postgraduate program. For such purpose, we reflect on the conditions and the effects of displacing concepts between the individual clinic of psychological suffering and the empirical research involving institutions and groups. Focusing on the affirmation of unconscious primacy, as the fundamental object of psychoanalytic technique, the authors seek to order the lines of approach and distance between clinic and empirical research. This process starts from the discussion about the necessary conditions, outside the therapeutic setting, to listen to the unconscious, to the establishment of transferential bond, to the interpreting work of subjects' discourses, and finally, to the elaboration of unconscious contents and desires, either by the subjects listened to the research or by the researcher himself in his theoretical elaboration.

Keywords: psychoanalysis; research; methodology.

\section{Cuatro condiciones para la investigación en psicoanálisis}

Resumen: Este artículo discute el uso del psicoanálisis, en especial la técnica psicoanalítica basada en la asociación libre en investigaciones en el campo de la psicología social, a partir de la experiencia de autores en un programa de postgrado. Para tanto, se intenta producir una reflexión sobre las condiciones y los impactos del desplazamiento de conceptos entre la clínica del sufrimiento psíquico individual y la investigación empírica de instituciones y grupos. Centrándose en la afirmación del primado del inconsciente, los autores buscan ordenar las líneas de aproximación y de alejamiento entre la clínica y la investigación empírica. Se parte de la discusión sobre las condiciones necesarias, fuera del setting terapéutico, a la escucha 
del inconsciente, al establecimiento del vínculo transferencial, al trabajo de interpretación de los discursos de los sujetos y, por último, a la elaboración de contenidos y deseos inconscientes, ya sea por parte de los sujetos escuchados en la investigación, o del propio investigador en su trabajo de elaboración teórica.

Palabras clave: psicoanálisis; investigación; metodología.

\section{Quatre conditions pour la recherche en psychanalyse}

Résumé: Cet article traite de l'utilisation de la psychanalyse - en particulier de la technique psychanalytique basée sur l'association libre dans la psychologie sociale - à partir de l'expérience des auteurs dans un programme de troisième cycle. Pour ce faire, nous réfléchirons aux conditions et aux impacts du déplacement des concepts entre la clinique de la souffrance psychique individuelle et la recherche empirique impliquant des institutions et des groupes. En se concentrant sur l'affirmation de la primauté de l'inconscient, objet fondamental de la technique psychanalytique, les auteurs cherchent à ordonner les lignes d'approche et de distance entre les recherches clinique et empirique. Nous discutons les conditions nécessaires, en dehors du cadre thérapeutique, pour l'écoute de l'inconscient, pour l'établissement du lien transférentiel, pour l'interprétation des discours des sujets, et enfin, pour l'élaboration des contenus et des désirs inconscients ; soit par les sujets de recherche, ou par le chercheur lui-même dans son travail d'élaboration théorique.

Mots-clés: psychanalyse ; recherche ; méthodologie.

\section{Referências}

Aragão, L. T., Calligaris, C., Costa, J. F., \& Souza, O. (1991). Clínica do Social: Ensaios. São Paulo, SP: Escuta.

Batista, K. R. O. (2011). Entre torcer e ser banido, vamos nos (re)organizar: Um estudo psicanalitico da torcida Trovão Azul. Dissertação de Mestrado, Departamento de Psicologia, Universidade Federal de Sergipe, São Cristóvão.

Batista, K. R. O., \& Cunha, E. L. (2012). A experiência psicanalítica na investigação social: considerações sobre método. ECOS: Estudos Contemporâneos da Subjetividade, 2(2), 261-275.

Birman, J. (1994). A direção da pesquisa psicanalítica. In J. Birman, Psicanálise, ciência e cultura (pp. 13-27). Rio de Janeiro, RJ: Zahar.

Coelho, D., \& Birman, J. (2014) A transferência na pesquisa em psicanálise - um ponto de vista ético. In J. Birman, D. Kupermann, E. L. Cunha, \& L. Fulgencio (Orgs.), A fabricação do humano: Psicanálise, subjetivação $e$ cultura (pp. 125-136). São Paulo, SP: Zagodoni.

Cunha, E., \& Coelho, D. (2015). Recomendações ao pesquisador que pratica a psicanálise. In A. Faro, M. Mendonça Filho, \& R. Henriques. Políticas do social Avesso da razão (pp. 94-104). São Cristóvão, SE: EdUFS.

Figueiredo, A. C. (1997). Vastas confusões e atendimentos imperfeitos: a crítica psicanalítica no ambulatório público. Rio de Janeiro, RJ: Relume Dumará.

Fonseca, E. E. P. F. (2015). Mulheres em situação de abrigamento: uma abordagem a partir da inserção em uma casa-abrigo. Dissertação de Mestrado, Programa de Pós-Graduação em Psicologia Social, Universidade Federal de Sergipe, São Cristóvão.

Freud, S. (1969). A interpretação dos sonhos. In Edição standard brasileira das obras completas de Sigmund
Freud. (Vol. 4-5IV). Rio de Janeiro, RJ: Imago. (Trabalho original publicado em 1900)

Freud, S. (1969). Construções em análise. In Edição standard brasileira das obras completas de Sigmund Freud (Vol. 23, pp. 289-304). Rio de Janeiro, RJ: Imago. (Trabalho original publicado em 1937)

Freud, S. (1969). Lembranças encobridoras. In Edição standard brasileira das obras completas de Sigmund Freud (Vol. 2, pp. 333-358). Rio de Janeiro, RJ: Imago. (Trabalho original publicado em 1899)

Freud, S. (2010). A dinâmica da transferência. In Obras completas (Vol. 10, pp. 133-239). São Paulo, SP: Companhia das Letras. (Trabalho original publicado em 1912a)

Freud, S. (2010). Luto e melancolia. In Obras completas (Vol. 12, pp. 170-194). São Paulo, SP: Companhia das Letras (Trabalho original publicado em 1917).

Freud, S. (2010). Observações sobre o amor de transferência. In Obras completas (Vol. 10, pp. 211-228). São Paulo, SP: Companhia das Letras. (Trabalho original publicado em 1915a)

Freud, S. (2010). O uso da interpretação dos sonhos na psicanálise. In Obras completas (Vol. 10 p. 112-132). São Paulo, SP: Companhia das letras. (Trabalho original publicado em 1911)

Freud, S. (2010). Os instintos e seus destinos. In Obras completas (Vol. 12, pp. 51-81). São Paulo, SP: Companhia das Letras. (Trabalho original publicado em 1915b)

Freud, S. (2010). Recomendações ao médico que prática a psicanálise. In Obras completas. Vol. 10, pp. 147-162). São Paulo, SP: Companhia das Letras. (Trabalho original publicado em 1912b) 
Freud, S. (2010). Recordar, repetir, elaborar. In Obras completas (Vol. 10, pp. 193-209). São Paulo, SP: Companhia das Letras. (Trabalho original publicado em 1914)

Freud, S. (2011). Autobiografia. In Obras completas (Vol. 16, p. 75-167). São Paulo, SP: Companhia das Letras. (Trabalho original publicado em 1925)

Freud, S. (2011). Psicologia das massas e análise do eu. In Obras Completas. São Paulo, SP: Companhia das Letras, v. XV, p. 13-113 (Trabalho original publicado em 1921).

Freud, S. (2014). Pressupostos e técnicas da interpretação. In Obras completas (Vol. 13. p. 133-150). São Paulo, SP: Companhia das Letras. (Trabalho original publicado em 1916-1917)

Lacan, J. (1999). Intervenção sobre a transferência. In Escritos (p. 214-228). Rio de Janeiro, RJ: Zahar. (Trabalho original publicado em 1966)

Lo Bianco, A. C. (2003). Sobre as bases dos procedimentos investigativos em psicanálise. PsicoUSF, 8(2), 115-124.

Malan, D. (1981). As fronteiras da psicoterapia breve. Porto Alegre, RS: Artes Médicas.

Rosa, M. D. (2016). A clínica psicanalítica em face da dimensão sociopolítica do sofrimento. São Paulo, SP: Escuta.

Rosa, M. D., \& Domingues, E. (2010). O método na pesquisa psicanalítica de fenômenos sociais e políticos: a utilização da entrevista e da observação. Psicologia \& Sociedade, 22(1), 180-188.
Santana, A. S. (2015). O processo de desligamento de jovens de abrigo institucional para crianças e adolescentes. Trabalho de Conclusão de Curso, Departamento de Psicologia, Universidade Federal de Sergipe, São Cristóvão.

Santos, E. M. F. (2012). Processos de subjetivação de pessoas que vivem com HIV/AIDS: considerações acerca de um grupo de adesão ao tratamento. Dissertação de Mestrado, Programa de Pós-Graduação em Psicologia Social, Universidade Federal de Sergipe, São Cristóvão.

Sobral, A. L. O. (2013). Cirurgia bariátrica: fragmentos da análise de uma espera. Dissertação de Mestrado, Programa de Pós-Graduação em Psicologia Social, Universidade Federal de Sergipe, São Cristóvão.

Souza, C. R. A. (2012). Politicas públicas de assistência social em análise: história, valores e práticas. Dissertação de Mestrado, Programa de Pós-Graduação em Psicologia Social, Universidade Federal de Sergipe, São Cristóvão.

Souza, C. R. A., \& Coelho, D. (2014). Ideais e perversidades em jogo nas políticas públicas de assistência social: Uma leitura psicanalítica dos valores e práticas. Tempo Psicanalítico, 46(2), 253-269.
Recebido: 28/11/2019

Revisado: 22/6/2020

Aprovado: 1/3/2021 